\section{Medikamentöse Therapie von Hauttumoren}

Für die medikamentöse Therapie von Hauttumoren stehen neben verschiedenen Zytostatika und Immunmodulatoren auch spezifisch in die Signaltransduktion von Tumoren eingreifende Substanzen zur Verfügung.

Das verbesserte Verständnis der Pathogenese von Hauttumoren zusammen mit den innovativen Methoden der medizinische Chemie, ermöglichte die rasante Entwicklung von Arzneistoffen mit zum Teil völlig neuen Wirkmechanismen. In diesen spannenden Zeiten des Umbruchs, widmet Der Hautarzt diesen Entwicklungen das

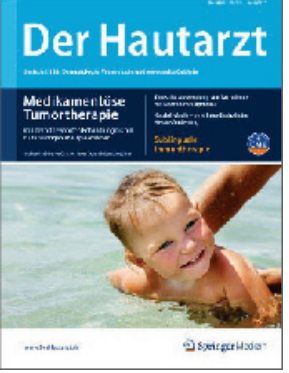
Leitthemenheft 06/2011. In folgenden Beiträgen wird der Bogen von der „altbewährten" Therapie über die neuen Substanzen bis zu den zukünfti-

gen Therapieansätzen gespannt:

- Adjuvante systemische Therapie des Melanoms

- Therapie des inoperabel metastasierten Melanoms

- Medikamentöse Therapie nichtmelanozytärer epithelialer Tumore

- Systemische Therapie kutaner Lymphome

- Kutane Nebenwirkungen der medikamentösen Tumortherapie

Bestellen Sie diese Ausgabe zum Preis von EUR 34,- zzgl. Versandkosten bei: Springer Customer Service Center GmbH Kundenservice Zeitschriften Haberstr. 7

69126 Heidelberg

Tel.: +49 6221-345-4303

Fax: +49 6221-345-4229

leserservice@springer.com

P.S. Mehr rund um Ihr Fachgebiet finden Sie auf www.springermedizin.de
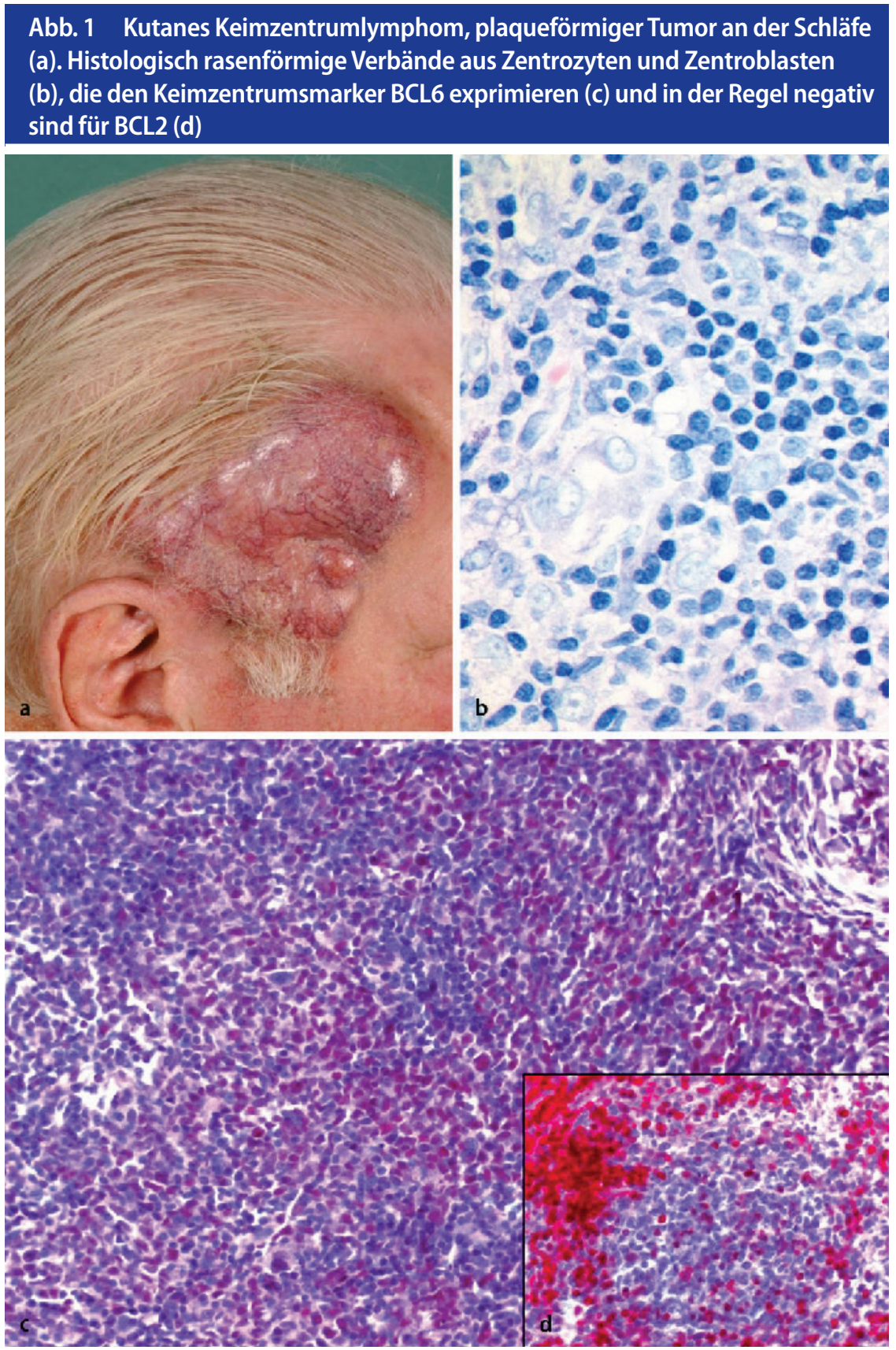

(- Abb. 2) und gilt als kutanes Gegenstück zu den MALT-Lymphomen („mucosa associated lymphoid tissue"). Deshalb wurde seinerzeit der inzwischen unüblich gewordene Begriff SALT („skin associated lymphoid tissue") geprägt. Diese Analogie hinkt jedoch, da in der Haut ortständiges lymphatisches B-ZellGewebe nicht vorkommt [10].

Das primär kutane Marginalzonenlymphom unterscheidet sich vom primär kutanen Keimzentrumlymphom, dessen Effloreszenzen klinisch ähnlich sind, in seinem Verteilungsmuster mit Prädilektion an Stamm und oberen Extremitäten, während die Kopf-Hals-Region nur selten betroffen ist. Inwieweit ein chronischer Immunstimulus, vor allem durch Infektion mit Borrelia burgdorferi oder Kolonisation mit Helicobacter pylori, pathogenetisch involviert sein könnte, ist Gegenstand der aktuellen Diskussion 